\title{
CPR on Admission in Severely Injured Patients- is it a Prognostic Factor for Evaluation of Traumatic Patients?
}

\section{Faruquzzaman ${ }^{1 *}$, Mazumder $\mathbf{S K}^{2}$ and Rahman $\mathbf{M M}^{3}$}

${ }^{1}$ Honorary Medical Officer, Surgery Unit 2 Khulna Medical College Hospital, Khulna, Bangladesh ${ }^{2}$ Director NIPSOM, Dhaka, Bangladesh

${ }^{3}$ Assistant Registrar, Surgery Unit 1 Khulna Medical College Hospital, Khulna, Bangladesh

\begin{abstract}
In the medical practice, the different scenarios in which cardio-respiratory resuscitation (CPR) may be applied must be taken into account. It is also critical in hospitalized patients with potentially reversible diseases, who suffer cardiac arrest as an unexpected event during their evolution. In this study, it has been found that necessity of CPR on admission reflects the worst prognosis for a traumatic patient, as it has been observed that the mortality rate is indeed hundred percent within the first 72 hours of admission. So, necessity of CPR on arrival could be a good prognostic factor in clinical practice when handling the severely injured patients. This study was conducted with a view to assess the role of CPR as a prognostic factor for the traumatic emergency patients admitted in the hospital at an emergency basis. In this study, it has been observed that on admission, 21 patients out of total 822 patients required immediate resuscitation with CPR and all of them ultimately died within 72 hours after arrival in course of the treatment. This study suggests that 11 patients $(52.4 \%)$ died within first 6 hours of admission, $9(42.9 \%)$ patients died with $6-24$ hours and 1 patient $(4.8 \%)$ died within 24-72 hours. 12 out of 21 patients were admitted with arterial blood pressure of 0/0 $\mathrm{mmHg}$ together with non-recordable pulse and all were dead within the first 6 hours of arrival.
\end{abstract}

\section{Keywords: CPR; Trauma; Prognosis; Mortality rate}

\section{Introduction}

In the medical practice, the different scenarios in which cardiorespiratory resuscitation (CPR) may be applied must be taken into account. CPR is crucial in patients that arrive in emergency rooms or suffer a cardiac arrest in public places or in their homes. It is also critical in hospitalized patients with potentially reversible diseases, who suffer cardiac arrest as an unexpected event during their evolution [1].

The latest guidelines for CPR and emergency cardiovascular care published by the American Heart Association include substantial changes to the algorithms for basic life support and advanced cardiovascular life support [2].

The most critical emergency situation seen in cardiac surgical units is the need for chest reopening. While senior nurses often manage cardiac arrest, they currently are not trained to open chests, which can be a life-saving action if performed efficiently [3]. The ability to respond quickly and effectively to a cardiac arrest situation rests on nurses being competent in the emergency life-saving procedure of CPR. The study findings present strong evidence to support the critical role of $\mathrm{CPR}$ training in ensuring that nursing student's progress to competent and confident responders in the event of a cardiac related emergency [4].

The ability to respond quickly and effectively to a cardiac arrest situation rests on nurses being competent in the emergency life-saving procedure of cardiopulmonary resuscitation. A total of 13301 accident victims treated in the accident and emergency department of Hospital de Base in São José do Rio Preto between July 2004 and December 2006 were evaluated in a prospective study. Patients requiring immediate cardiovascular resuscitation on admission were identified. The types of injury and survival of these patients were evaluated.

Of the 65 patients included in that study, 30\% had suffered from gunshot wounds, $19 \%$ had been run over, $18 \%$ had been involved in car crashes, $13 \%$ in motor cycle accidents, $9 \%$ stabbings, $1 \%$ by cycle accidents and $10 \%$ other types of accidents including burns, hangings, and falls. In only 12 of these patients, immediate resuscitation was successful and procedure such as chest drainage, exploratory laparotomy and interventions in the surgical center were performed. However all patients evolved to death; eight within 24 hours, two between 24 and 48 hours and the other 2 after 48 hours. Immediate cardiopulmonary resuscitation after accidents is a sign of high mortality requiring further studies to review indication and the ethical aspects involved $[5,6]$.

That study shows that immediate cardiopulmonary resuscitation is a factor for high mortality in victims of trauma emergencies. The few published studies on this subject confirm this high mortality rate $[7,8]$. Instead of insisting on aggressive measures to resuscitate trauma patients in extremis on presentation, the authors suggest we should redirect that fervor toward efforts made to promote trauma awareness and injury prevention programs [8]. Another aspect to be evaluated is the cost of these interventions for patients who have a low probability to survive. Studies show that the duration of cardiopulmonary resuscitation was positively associated with the elevation of cardiac markers [9]. Study related that we cannot decide to give up and terminate resuscitation in any cardiopulmonary arrest on arrival due to penetrating trauma patients and cannot define salvageable patients. However, our data show that 30 -min resuscitation is thought to be relevant and that we should not give up on resuscitation because of the time interval without return of spontaneous circulation after arrival at the hospital [10].

In the context of a community-wide focus on resuscitation, the sequential implementation of 2005 American Heart Association guidelines for compressions, ventilations, and induced hypothermia significantly improved survival after cardiac arrest. Further study is

${ }^{*}$ Corresponding author: Faruquzzaman, C/O: Md. Moazzem Hossain, 7, Islambag Road, Railygate, Daulatpur- 9202, Khulna, Bangladesh, Tel: +8801742456376; E-mail: drfaruquzzaman@yahoo.com

Received May 22, 2012; Accepted July 20, 2012; Published July 23, 2012

Citation: Faruquzzaman, Mazumder SK, Rahman MM (2012) CPR on Admission in Severely Injured Patients- is it a Prognostic Factor for Evaluation of Traumatic Patients? Surgery Curr Res 2:122. doi:10.4172/2161-1076.1000122

Copyright: (C) 2012 Faruquzzaman, et al. This is an open-access article distributed under the terms of the Creative Commons Attribution License, which permits unrestricted use, distribution, and reproduction in any medium, provided the original author and source are credited. 
required to clarify the relative contribution of each intervention to improved survival outcomes [11].

Trauma was estimated to have caused $10 \%$ of all deaths occurring in 1990 world-wide [12]. Trauma remains the third largest cause of death in all regions of the world [13]. If young people only are considered, trauma becomes the leading cause of death and is thus the greatest source of potential years of life lost [14]. It was calculated that in 1990, intentional and unintentional injuries caused $10 \%$ of mortality worldwide, but $15 \%$ of DALYs [15].

Between 1990 and 1994, the annual growth rate fell to $1.57 \%$, but again, there is a marked difference between rates in developed and developing countries. In the developing world between 1990 and 1995, the population growth rate was $2.8 \%$ per annum, compared to $0.4 \%$ in the industrialized nations [16].

It has been claimed that the recent decrease in homicides in the USA can be attributed, in part, to the diminishing number of young men [17]. Another influential factor affecting patterns of injury all over the world is the increasing use of alcohol and other drugs. In one study, about $50 \%$ of people dying from injury tested positive for blood alcohol [18]. Some $56 \%$ of all the trauma admissions to the orthopedic department of a New Orleans hospital during 1993 and 1994 tested positive for drugs or alcohol, rising to $71 \%$ of those admitted with gunshot wounds [19]. In the UK, the Department of Transport estimated that in the 11 months before October 1996, 25\% of road fatalities had taken drugs, $20 \%$ of which were illicit substances [20]. A pedestrian who has been drinking is two-and-a-half times more likely to be involved in a road traffic accident (RTA) than one who has not [21]. Stinson and De Bakey [22] found that alcohol-related deaths in the USA actually fell during the 1980s, largely due to an improvement in the drink-driving figures [23]. By 1992 in the same age group, not only had the number of deaths resulting from trauma fallen to 487 per million, but only $46 \%$ of these were caused by RTAs [24,25].

Currently, numbers of suicides are increasing, and suicides are forming a larger proportion of violent deaths. This would appear to parallel the large increase in mental illness, and particularly unipolar depression, reported by the World Health Organization (WHO) during the past decade. Between $60 \%$ and $80 \%$ of suicides are associated with depression [26]. Sometimes, however, there is a reluctance to classify deaths as suicides. For example, in Roman Catholic countries, where suicide is regarded as a mortal sin by the Church, many such deaths are classified as accidental or of undetermined cause. Greece, Italy and Spain have among the lowest suicide rates in Europe [26]. The USA and Europe has shown a general increase in suicide over the last three decades, particularly among 15 - to 24 -year-old men. There are one or two exceptions to this [27].

The USA is unusual in that it is an established market economy with a relatively high homicide rate. Between 1975 and 1992, the overall annual male homicide rate remained steady at about 16 per 100 000 population, yet at the same time the rate for 15- to 24-years old men rose from 21 to 37 per 100000 population [28,29].

Between 20\% and 30\% of all accidental deaths occur in the home $[29,30]$. For every death, there may be as many as four cases of permanent impairment [31]. The two age groups particularly at risk of domestic injury are children over the age of 1 year and adults over 65 years [32]. However, the elderly have a far higher mortality rate than the young; for example, in the UK, $12-13 \%$ of all domestic accidents occur in the over-65 age group, but these people suffer at least $70 \%$ of domestic deaths [33]. Children may have most of their accidents at home, but motor vehicles cause most of their deaths [34].

\section{Materials and Methods}

1) Type of study: Descriptive type of epidemiological crosssectional study.

2) Place of study: The general surgery indoor department of Khulna Medical College Hospital, Bangladesh.

3) Period of study: From 01-02-2010 to 30-07-2010

4) Sample size: 822

The sample size was selected by using the formula $\mathrm{Z} 2 \mathrm{pq} \times \mathrm{D}$

5) Sampling technique: Convenient type of purposive sampling.

6) Data analysis: After collection, data were checked, verified, compared, reviewed and analyzed according to the objectives and purposes of the study at NIPSOM, Bangladesh.

\section{Results}

This study was conducted with a view to assess the role of CPR as a prognostic factor for the traumatic emergency patients admitted in the hospital at an emergency basis. The age and sex distribution of the study population is described in table 1 .

In inquire of cause of different types trauma, it was found that the major contributing factor to such relation was road traffic accident (RTA), total 237 patients in $\mathrm{KMCH}$ which was $28.8 \%$ of all admission. The causes of trauma in total 822 admitted patients are represented in figure 1.

On admission, 21 (2.6\%) patients out of total 822 patients, required immediate resuscitation with CPR and all of them ultimately died within 72 hours after arrival in course of the treatment. This study suggest that 11 patients (52.4\%) died within first 6 hours of admission, $9(42.9 \%)$ patients died with $6-24$ hours and 1 patient $(4.8 \%)$ died within 24-72 hours (Table 2). 12 (57.1\%) patients out of 21 patients were admitted with arterial blood pressure of $0 / 0 \mathrm{mmHg}$ together with non-recordable pulse and all were dead within the first 6 hours of arrival.

\section{Discussion}

The ultimate aim of this study was to evaluate the CPR as a prognostic factor during clinical management of traumatic patient's in common surgical practice, not to assess the necessity of CPR in such

\begin{tabular}{|l|l|l|}
\hline Age group in year & Male & Female \\
\hline$\leq 10$ & 15 & 7 \\
\hline$\%$ & 1.8 & 0.9 \\
\hline $11-30$ & 111 & 93 \\
\hline$\%$ & 13.5 & 11.3 \\
\hline $31-50$ & 241 & 134 \\
\hline$\%$ & 29.3 & 16.3 \\
\hline $51-70$ & 96 & 56 \\
\hline$\%$ & 11.7 & 6.8 \\
\hline$>70$ & 42 & 27 \\
\hline$\%$ & 5.1 & 3.3 \\
\hline
\end{tabular}

Table 1: Age and sex distribution of the admitted traumatic patients.

\begin{tabular}{|l|l|l|l|}
\hline & First 6 hours & $6-24$ hours & $24-72$ hours \\
\hline Male & 9 & 8 & 1 \\
\hline Female & 2 & 1 & 0 \\
\hline Total & 11 & 9 & 1 \\
\hline
\end{tabular}

Table 2: Time of death from admission. 


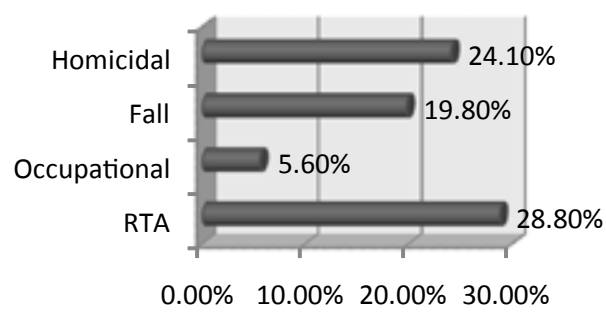

Figure 1: Causes of traumatic injury in admitted patients.

patient. 822 traumatic patients of different age groups and sex were included in this study as study population among whom $28.8 \%$ (237 out of total 822 patients) were admitted due to road traffic accident (RTA) in $\mathrm{KMCH}$, Bangladesh.

In this study, it has been observed that on admission 21 patients out of total 822 patients, required immediate resuscitation with CPR and all of them ultimately died within 72 hours after arrival in course of the treatment. This study also suggests that 11 patients (52.4\%) died within first 6 hours of admission, 9 (42.9\%) patients died with 6- 24 hours and 1 patient (4.8\%) died within 24-72 hours. 12 patients out of 21 patients were admitted with arterial blood pressure of $0 / 0 \mathrm{mmHg}$ together with non-recordable pulse and all were dead within the first 6 hours of arrival. So, these data of our study clearly suggest that if a patient requires $\mathrm{CPR}$ on admission, the prognostic outcome is catastrophic in such patient and mortality rate is $100 \%$, reflected by this study. But it does not mean that the patient does not require CPR on evaluation.

\section{Conclusion}

Necessity of CPR on admission reflects the worst prognosis for a traumatic patient, as it has been observed that the mortality rate is indeed hundred percent within the first 72 hours of admission.

\section{References}

1. Grupo de Estudios de Etica Clínica de la Sociedad Médica de Santiago (2007) [Cardiopulmonary resuscitation and do not resuscitate orders]. Rev Med Chil 135: 669-679.

2. Dawkins S, Deakin CD, Baker K, Cheung S, Petley GW, et al. (2008) A prospective infant manikin-based observational study of telephonecardiopulmonary resuscitation. Resuscitation 76: 63-68.

3. Danitsch D, Levine A, Choudrey S, Dunning J, Ariffin S, et al. (2006) Evaluation of a cardiac surgery advanced life support course. Nurs Times 102: 30-32.

4. Madden C (2006) Undergraduate nursing students' acquisition and retention of CPR knowledge and skills. Nurse Educ Today 26: 218-227.

5. Luciano BA, Marcela GF, Cesar EP, de Godoy JM (2010) Necessity of immediate cardiopulmonary resuscitation in trauma emergency. World J Emerg Surg 5: 25.

6. http://www.wjes.org/content/5/1/25

7. Alanezi K, Alanzi F, Faidi S, Sprague S, Cadeddu M, et al. (2004) Survival rates for adult trauma patients who require cardiopulmonary resuscitation. CJEM 6 : 263-265.

8. Lo CJ, Chang WL (2007) Management of pulseless and apneic trauma patients: are aggressive measures justified? Am Surg 73: 62-66.
9. Polena S, Shen KH, Mamakos E, Chuang PJ Sharma M, et al. (2005) Correlation between cardiac enzyme elevation and the duration of cardiopulmonary resuscitation. Proc West Pharmacol Soc 48: 136-138.

10. Moriwaki Y, Sugiyama M, Toyoda H, Kosuge T, Tahara Y, et al. (2010) Cardiopulmonary arrest on arrival due to penetrating trauma. Ann R Coll Surg Engl 92: 142-146.

11. Hinchey PR, Myers JB, Lewis R, De Maio VJ, Reyer E, et al. (2010) Improved out-of-hospital cardiac arrest survival after the sequential implementation of 2005 AHA guidelines for compressions, ventilations, and induced hypothermia: the Wake County experience. Ann Emerg Med 56: 348-357.

12. Murray CJL, Lopez AD (1996) The Global Burden of Disease. In: Murray CJL, Lopez AD. (1st ed.) Global Burden of Disease and Injury. The Harvard School of Public Health.

13. Bourbeau R (1993) [Comparative analysis of mortality due to violence in developed countries and in a few developing countries during the 1985-1989 period]. World Health Stat Q 46: 4-32.

14. Trunkey DD (1983) Trauma. Scientific American 249: 20-27.

15. Murray CJL, Lopez AD (1997) Mortality by cause for eight regions of the world: global burden of disease study. Lancet 349: 1269-1276.

16. Global socio-economic development trends (1985-1989). World Health Statistics Quarterly 42: 190-196.

17. Dejevsky M (1997) Gun deaths fall in US - as road toll picks up speed. The Independent.

18. Goodman RA, Istre GR, Jordan FB, Horndon JL, Kelaghan J (1991) Alcoho and fatal injuries in Oklahoma. Journal of Studies on Alcohol 52: 156-161.

19. Levy RS, Hebert CK, Munn BG, Barrack RL (1996) Drug and alcohol use in orthopedic trauma patients: a prospective study. J Orthop Trauma 10: 21-27.

20. English S (1997) 'Lollipop' may lick problem of drivers on drugs. The Times.

21. Irwin ST, Patterson CC, Rutherford WH (1983) Association between alcoho consumption and adult pedestrians who sustain injuries in road traffic accidents. Br Med J (Clin Res Ed) 286: 522.

22. Stinson FS, DeBakey SF (1992) Alcohol-related mortality in the United States, 1979-1988. Br J Addict 87: 777-783.

23. Walsh B, Grant M (1985) International trends in alcohol production and consumption: implications for public health. World Health Stat Q 38: 130-141.

24. HMSO (1997) International Comparisons of Transport Statistics (1 st ed.) London.

25. HMSO (1993) Office of Population Censuses and Surveys. Mortality Statistics - Cause. London.

26. Diekstra RF, Gulbinat W (1993) The epidemiology of suicidal behaviour: a review of three continents. World Health Stat Q 46: 52-68.

27. Wolfgang ME (1986) Homicide in other industrialized countries. Bull N Y Acad Med 62: 400-412.

28. World Health Organization (1976) World Health Statistics Annual (1973-1976) Geneva.

29. World Health Organization (1996) World Health Statistics Annual(1995) Geneva.

30. Waters E, Cliff K (1981) Accidents will happen. Nursing Mirror 153: 46-47.

31. Lang-Runtz H (1983) Preventing accidents in the home. Can Med Assoc J 129 482, 484-485.

32. Department of Trade and Industry (1987) Home Accident Surveillance System Home and Leisure Accident Research: Eleventh Annual Report, London.

33. Poyner B (1986) Home and Leisure Accident Research - The Elderly. London: Department of Trade and Industry.

34. Mazurek AJ (1994) Epidemiology of paediatric injury. J Accid Emerg Med 11 9-16. 